\title{
HIV/AIDS: o documento de Santiago de Compostela
}

\author{
Adotado na $6^{\text {a }}$ Conferência Mundial de Saúde Rural da WONCA
}

Santiago de Compostela, Espanha, 26 de setembro de 2003

WONCA Working Party on Rural Practice

Nós, enquanto médicos assistentes rurais na 6a Conferência Mundial de Saúde Rural da WONCA em Santiago, estamos profundamente preocupados com a extensão do crescimento da pandemia do HIV/AIDS e o modo que isso exacerba os problemas de pobreza, desigualdade e subdesenvolvimento no mundo.

Nós reconhecemos que esse é um problema global. Nós vivemos em um mundo interdependente. Nenhum de nós pode permanecer alheio. Todos nós somos afetados, se não infectados.

\section{Nós acreditamos:}

- Que é crucial voltar-se para a questão do HIV/AIDS em termos de atenção primária à saúde, sistemas de atenção à saúde e organizaçóes internacionais; e

- Que os países desenvolvidos têm uma responsabilidade moral de trabalhar em direção a um cuidado equânime dos infectados com HIV/AIDS em todas as partes do mundo.

\section{Nós, portanto:}

1. Comprometemo-nos a trabalhar com outros profissionais de saúde, organizaçôes não governamentais e comunidades para garantir uma resposta abrangente e equânime para o HIV/AIDS ao nível de atenção primária, dentro da filosofia de Saúde para Todos;

2. Apoiar uma abordagem abrangente do problema que inclui desde tratamento apropriado e com recursos adequados, e estratégias preventivas amplas (incluindo práticas médicas seguras, educação sobre os riscos, promoção da mudança de comportamento, prevenção da transmissão materno-infantil, etc.); e

\section{Solicitar à WONCA}

- reconhecer a importância crucial e a urgência da situação relacionada a HIV/AIDS; e

- reunir países membros e agências internacionais para comprometerem recursos para o problema, especialmente nos países em desenvolvimento, reconhecendo a importância, tanto do fortalecimento dos sistemas locais de atenção à saúde como da atençáo aos problemas de pobreza global, injustiça e desigualdades que alimentam a propagação do HIV/AIDS.

Tradução para a versão brasileira: André L. Silva

Rio de Janeiro: SBMFC, 2011 